\title{
EFEITO DE ALGUNS TRATAMENTOS TÉRMICOS SOBRE A MICROESTRUTURA E PROPRIEDADES MECÂNICAS DE UM AÇO MICROLIGADO*
}

\author{
Tainan Ferreira Muniz ${ }^{1}$ \\ Milena Kellen Oliveira Mendes ${ }^{2}$ \\ Vicente Braz Trindade Filho ${ }^{3}$ \\ Geraldo Lúcio de Faria ${ }^{4}$
}

\section{Resumo}

O presente trabalho estudou a influência de alguns tratamentos térmicos sobre a microestrutura e as propriedades mecânicas de um aço microligado visando à adequação de parâmetros que o classifiquem como um ao do tipo API X65 paraaplicação na prospecção e condução de óleo e gás. Diferentes ciclos de tratamentos térmicos envolvendo normalização, têmpera e revenimento foram aplicados a amostras deste aço. Estas foram submetidas a ensaios de tração, dureza Vickers e impacto Charpy, além de terem sido microestruturalmente caracterizadas com o auxílio de microscopia ótica e eletrônica de varredura. Observou-se que as microestruturas e propriedades mecânicas foram fortemente influenciadas pelos tratamentos estudados. Entretanto, apenas a amostra temperada e revenida atendeu integralmente aosrequisitos para o grau API X65no que diz respeito às propriedades mecânicas. Estaamostratambémapresentou maior a tenacidade ao impacto, o que está associado ao alívio de tensões e à decomposição da martensitae da bainita em carbonetos de ferro e ferrita. A amostra normalizada apresentou microestrutura constituída por perlita e ferrita, possuindo assim os menores limites de resistência mecânica e a maior ductilidade. Já nas espécies normalizada-temperada, assim como na simplesmente temperada, observou-semartensita e bainitacomo principais constituintes, supondo-se a presença de uma pequena fração de constituinte MA.

Palavras-chave:Aço microligado; Tratamentos térmicos; API X65.

\section{EFFECT OF SOME HEAT TREATMENTS ON THE MICROSTRUCTURE AND MECHANICAL PROPRIETIES OF A MICROALLOYED STEEL}

\section{Abstract}

The present work studied the influence of some heat treatments on microstructure and mechanical proprieties of a microalloyed steel aiming to adequate its properties to get the API X65 grade, to possibility its application in oil and gas industry.Tensile tests, Vickers hardness and Charpyimpacttests were performed, as well structural characterization byoptical and scanning electron microscopy. It was observed that steel microstructure and mechanical properties were significantly affected by the studied heat treatments. However, only the quenched and tempered specimen fulfilled the API X65 level in terms of mechanical proprieties. This sample also presented the higher toughness assigned to stress relieving and decomposition of the martensite and bainite in iron carbides and ferrite. The normalized sample exhibited microstructure composed of perlite and ferrite, thus having the lowesttensile strength parameters and the highest ductility. On normalized-quenchedandquenchendspecimens,martensite and bainite were observed as the main steel constituents with a small amount of MA.

Keywords: Microalloyed steel;Heat treatments; API X65.

Graduanda em Engenharia Metalúrgica, Estudante, DEMET, Universidade Federal de Ouro Preto, Ouro Preto, Minas Gerais, Brasil.

Graduanda em Engenharia Metalúrgica, Universidade Federal de Ouro Preto, Ouro Preto, MG, Brasil.

Doutor,Gerente de Pesquisa e Desenvolvimento,Vallourec\& Sumitomo Tubos do Brasil, Jeceaba, Minas Gerais, Brasil.

4 Doutor, Professor, DEMET, REDEMAT, Universidade Federal de Ouro Preto, Minas Gerais, Brasil. 


\section{INTRODUÇÃO}

O petróleo é amplamente utilizado pela humanidade devido à possibilidade de obtenção de produtos como óleo combustível, graxas, gasolina, parafina, vaselina e óleos lubrificantes [1]. Torna-se cada vez mais importante desenvolver técnicas que possibilitem extraí-lo, sendo que um dos principais desafios está na sua prospecção e condução. Os materiais metálicos utilizados nessa função precisam suportar situações extremas de solicitação mecânica, corrosão e temperaturas de trabalho. Para o Brasil, o desafio tornou-se ainda maior com a possibilidade de extração de petróleo e gás de camadas profundas, como a do pré-sal, onde o ambiente é ainda mais severo [2].

Os materiais que são amplamente utilizados para prospectar e transportar óleo e gás são tubos feitos de aços API. Esses aços atendem a um conjunto de normas criadas pela "American PetroleumInstitute" - API, que uniformizam os requisitos necessários para o fornecimento desses aços [3]. É usual esperar destes materiais: elevada resistência mecânica, boa tenacidade à fratura em baixas temperaturas, boa soldabilidade, boa resistência à corrosão e à oxidação, entre outros [4]. Por exemplo, os aços do grau X65, que são comumente utilizados em condução de gás a alta pressão, [5] paraatenderema norma devem ter as seguintes propriedades: limite de escoamento (LE) mínimo de $450 \mathrm{MPa}$, limite de resistência (LR) mínimo de $535 \mathrm{MPa}$ e máximo de $762 \mathrm{MPa}$, razão máxima entre os limites de escoamento e de resistência entre (LE/LR) de 0.90 e alongamento mínimo de 22\% [6,7].

Tipicamente, os aços API X65 apresentam microestrutura constituída principalmente por ferrita, que pode assumir diferentes morfologias, como acicular ou poligonal. Abainita e o constituinte MA também são constituintes comuns dos aços que atingem este grau e são geralmente temperados e revenidos [8].

Essas ligas estão em constante desenvolvimento pretendendo aumento de produtividade e redução nos custos. Para isso, as propriedades do material são adequadas modificando-se a composição química do aço eaplicando-setratamentos térmicos específicos. Esses últimos são muito utilizados devido à facilidade de realizaçãodosensaios em laboratórios e de adequaçãodos procedimentos em escala industrial [3].

Os tratamentos térmicos de têmpera e revenimento são conhecidos por aumentarem a dureza e a resistência mecânica de aços, já a normalização gera um refinamento na microestrutura de ligas que possibilita a melhoria de algumas propriedades mecânicas [4,9]. Estas, entre outras possibilidades de tratamentos térmicos,vêm sendo estudadas em aços microligados visando alcançar propriedades que os classifiquem pelas normas API [10,11].

Considerando a importância das propriedades mecânicas e da microestrutura de aços API para a indústria de petróleo e gás, neste trabalho, visou-se estudar o efeito de alguns tratamentos térmicos sobre estas características de um aço microligado com o objetivo de adequação da sua rota industrial de processamento para atendimento do grau API X65 linepipe, visando qualificá-lo para aplicação na indústria de óleo e gás. 


\section{MATERIAIS E MÉTODOS}

\subsection{Materiais}

Amostras de um tubo sem costura, de um aço microligado, foram fornecidas pela empresa Vallourec\& Sumitomo Tubos do Brasil (VSB). O material foi retirado na direção longitudinal de um tubo. A Tabela 1 apresenta as faixas de especificação química do aço em questão.

Tabela 1. Especificação química do aço microligado estudado neste trabalho (\% em massa).

\begin{tabular}{lccccc}
\hline Elemento & Mínimo (\%) & Máximo (\%) & Elemento & Mínimo (\%) & Máximo (\%) \\
\hline $\mathrm{C}$ & 0,08 & 0,10 & $\mathrm{Ni}$ & 0,15 & 0,20 \\
\hline $\mathrm{Si}$ & 0,25 & 0,35 & $\mathrm{Al}$ & 0,020 & 0,040 \\
\hline $\mathrm{Mn}$ & 1,25 & 1,35 & $\mathrm{Ti}$ & - & 0,010 \\
\hline $\mathrm{P}$ & - & 0,015 & $\mathrm{~V}$ & - & 0,030 \\
\hline $\mathrm{S}$ & - & 0,002 & $\mathrm{~B}$ & - & 0,0008 \\
\hline $\mathrm{Cu}$ & 0,15 & 0,20 & $\mathrm{Nb}$ & 0,020 & 0,030 \\
\hline $\mathrm{Cr}$ & - & 0,20 & $\mathrm{H}(\mathrm{ppm})$ & - & 6 \\
\hline $\mathrm{Mo}$ & 0,080 & 0,120 & $\mathrm{~N}$ & - & 0,010 \\
\hline
\end{tabular}

\subsection{Procedimentos Experimentais}

\subsubsection{Tratamentos térmicos}

Os corpos de prova foram previamente usinados na geometria adequada para os ensaios mecânicos. Em seguida, foram submetidos aos tratamentos de normalização (N); normalização e têmpera (NT); têmpera (T); têmpera e revenimento (TR) de acordo com a Tabela 2. As amostras foram austenitizadas no Forno Industrial Heating modelo TEM PERT 30/N2. Algumas foram resfriadas em água com agitação suave no tanque Industrial Heating, modelo TOR/180/500/500. Paraorevenimento e normalização foi utilizado o Forno Industrial Heating, modelo TEMPER/R30/N2, sendo todos estes equipamentos da Empresa VSB.

Tabela 2. Identificação de amostras e parâmetros de tratamentos térmicos utilizados.

\begin{tabular}{lcccc}
\hline Amostra & Tratamentos & $\begin{array}{c}\text { Temperatura } \\
\left({ }^{\circ} \mathbf{C}\right)\end{array}$ & $\begin{array}{c}\text { Tempo de } \\
\text { encharque } \\
\text { (min) }\end{array}$ & $\begin{array}{c}\text { Meio de } \\
\text { resfriamento }\end{array}$ \\
\hline $\mathrm{N}$ & normalização & 920 & 20 & Ar calmo \\
\hline $\mathrm{NT}$ & normalização & 920 & 20 & Ar calmo \\
\cline { 2 - 5 } & têmpera & 920 & 15 & Água \\
\hline $\mathrm{T}$ & têmpera & 920 & 15 & Água \\
\hline $\mathrm{TR}$ & têmpera & 920 & 15 & Água \\
\cline { 2 - 5 } & revenimento & 620 & 20 & Ar calmo \\
\hline
\end{tabular}

Para cada ciclo de tratamento térmico, foram ensaiados três corpos de prova em cada ensaio mecânico.

\subsubsection{Ensaio de tração}

O ensaio de tração foi realizado à temperatura ambiente e de acordo com as normas ASTM E8/8M - 13 ${ }^{\text {a }}$ [12] e ASTM A370 - 12a [13]. A máquina utilizada foi EMIC $1000 \mathrm{kN}$, modelo DL -100000, equipada com software e um extensômetro, da VSB, 
que registrou os valores de limite de escoamento (LE), limite de resistência e o alongamento de percentual.

\subsubsection{Ensaios de dureza Vickers e impacto Charpy}

O ensaio de dureza Vickers foi realizado de acordo com a norma ASTM E384 11e1[14]. O ensaio de impacto Charpy ocorreu com o corpo de prova a $0^{\circ} \mathrm{C}$, de acordo com a norma ASTM E23 - 12c [15].

\subsubsection{Caracterização microestrutural}

As amostras para a análise microestrutural foram retiradas da ponta do corpo de prova de tração ou do corpo de prova de dureza. Em seguida, passaram pelo processo de lixamento e polimentometalográfico padrão. Após o polimento, as amostras foram atacadas pelo reativoNital $2 \%$, com tempo de imersão entre $5 \mathrm{~s}$ a $15 s$.

$\mathrm{Na}$ análise microestrutural, utilizou-se um microscópio óptico Olympus CX31 do Laboratório de Tratamentos Térmicos e Microscopia Optica (LTM) do DEMET-UFOP e o microscópio eletrônico de varredura marca VEGA 3 TESCAN com DETECTOR EDS OXFORD X-ACT que se encontra no Nanolab - REDEMAT - Universidade Federal de Ouro Preto (UFOP).

\section{RESULTADOS E DISCUSSÃO}

\subsection{Ensaios de Tração, Dureza Vickers e Impacto Charpy}

Os valores obtidos de limite de escoamento (LE), de limite de resistência (LR) e a razãoelástica (LE/LR) para cada tratamento térmico são apresentados na Figura 1. Os valores representados são a média dos três corpos de prova ensaiados para cada condição de tratamento térmico, com seus respectivos desvios padrão.

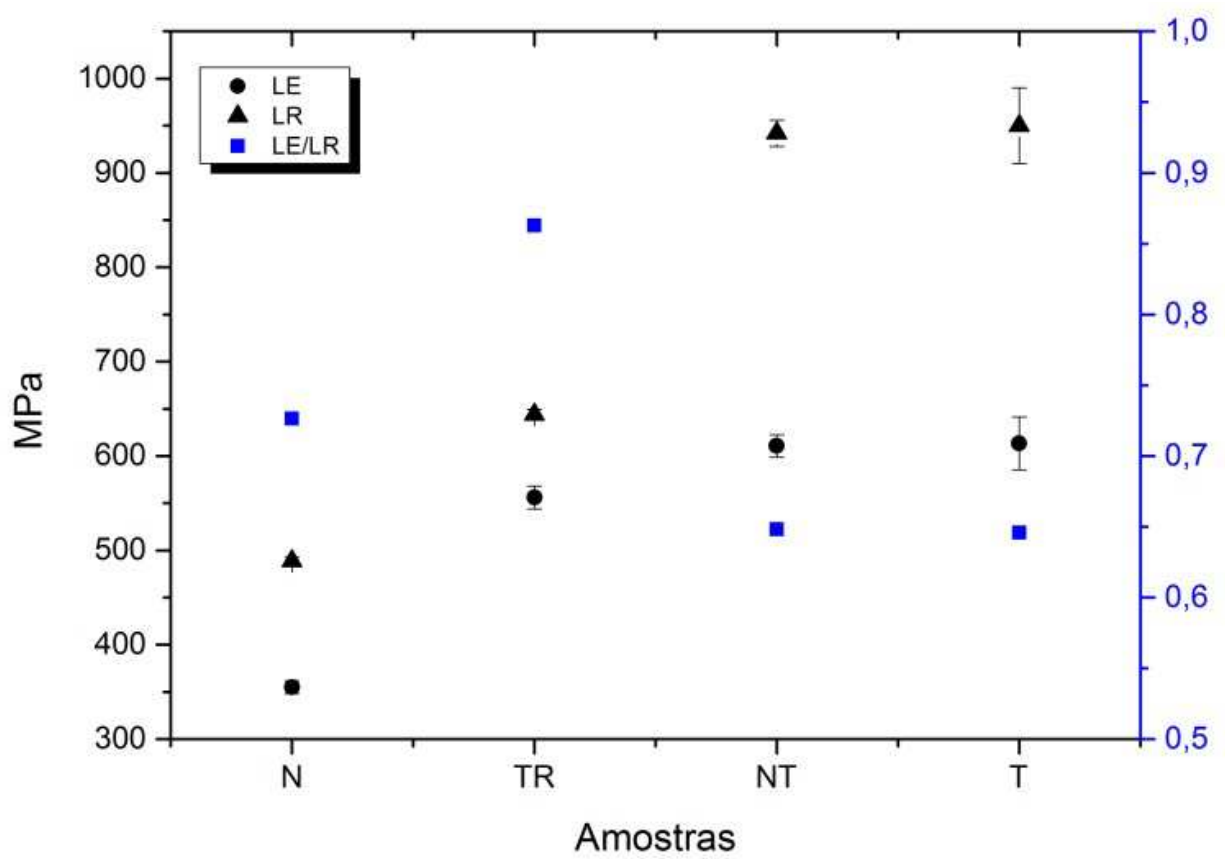

Figura 1. Valores de LE, LR e LE/LR dos tratamentos térmicos realizados.

Pode-se observar que os tratamentos térmicos estudados exercem significativa influência sobre as propriedades mecânicas avaliadas sob tração. Verifica-se que a 
amostra normalizada ( $\mathrm{N}$ ) apresentou os menores valores de limite de escoamento, assim como de limite de resistência. As amostras NT e T apresentaram os maiores valores de limite de escoamento e de limite de resistência, não havendo diferenças significativas entre elas.

Neste contexto, pode-se afirmar que o tratamento térmico de normalização realizado antes do de têmpera, com fins de homogeneização e refino de grão austenítico, não surtiu efeito significativo, uma vez que as amostras NT e T possuem comportamento semelhante sob tração [7]. A amostra temperada e revenida (TR) apresentou limite de escoamento ligeiramente inferior às NT e $T$, porém o seu limite de resistência a tração é muito inferior, indicando menor capacidade de encruamento durante deformação plástica uniforme.

Nota-se pela razão LE/LR, que todas as amostras atenderiam ao grau API X65 que exige um valor máximo de 0.90 [6].Entretanto, quando se analisa os valores de LE e LR a condição normalizada (N) não atende, pois não se alcança os valores mínimos estabelecidos pela norma [6]. Já as amostras T e NT ultrapassaram o máximo valor de LR. É possível entender melhor esse comportamento, ao se analisar as microestruturas de cada condição, que serão apresentadas e discutidas a seguir.

Os valores de alongamento são apresentados na Figura 2. Todas as amostras atingiram um valor mínimo de $22 \%$, atendendo o especificado para o grau API X65.

Verifica-se, como esperado, que a amostra $\mathrm{N}$ apresentou o maior alongamento, seguida das amostras TR, NT e T que não apresentaram significativas diferenças entre elas.

No contexto do ensaio de tração, pode-se afirmar que apenas a amostra TR atendeuintegralmenteàs especificações do grau API X65.

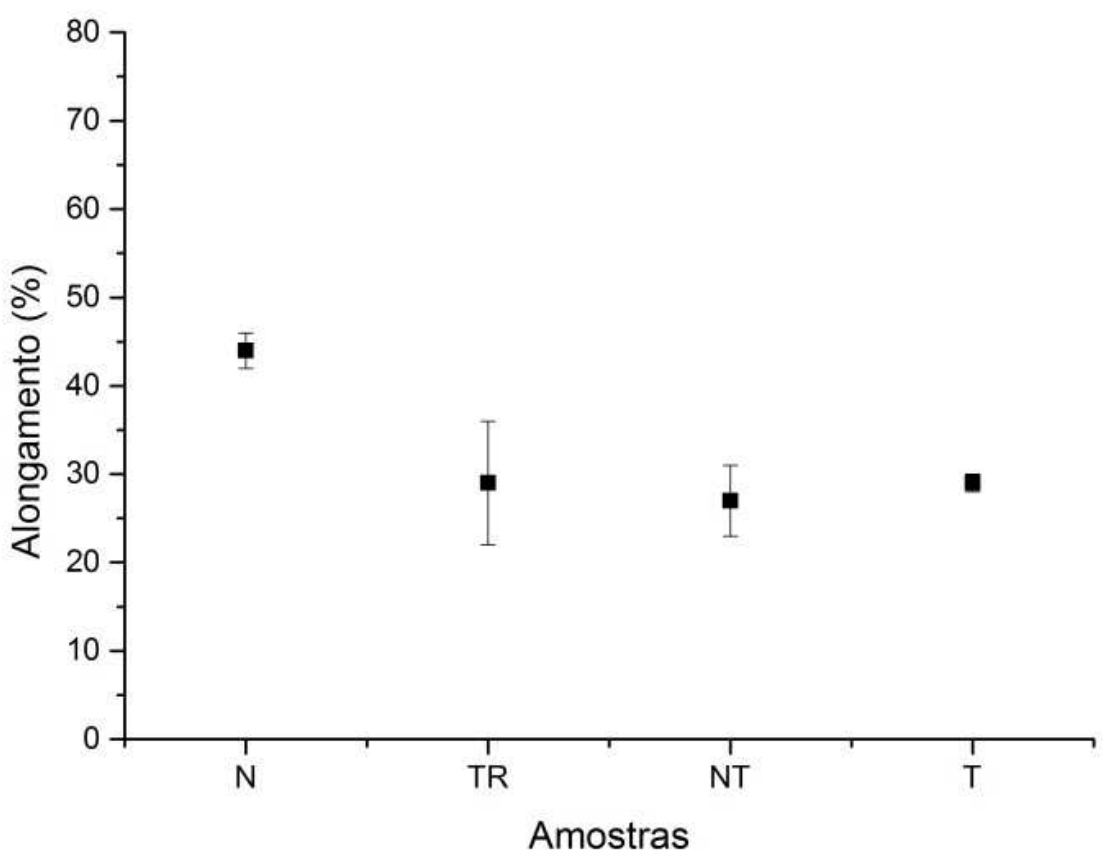

Figura 2. Alongamento das amostrastermicamente tratadas.

Para os ensaios de dureza Vickers e impacto Charpy, os dados obtidos estão na Figura 3. Observa-se que quanto maior a dureza, menor é a energia absorvida no ensaio de impacto. Nota-se que quando se compara os valores de LE das amostras TR, T e NT há pouca diferença entre elas, o que não ocorre ao se comparar a tenacidade ao impacto. O espécime TR apresenta um valor que quase é o dobro do 
das amostras T e NT. Conhecidamente, o tratamento térmico de revenimento é responsável por essa elevação, pois alivia tensões internas decorrentes das transformações de fase do aço durante a têmpera e diminui a densidade de discordâncias na estrutura [16].

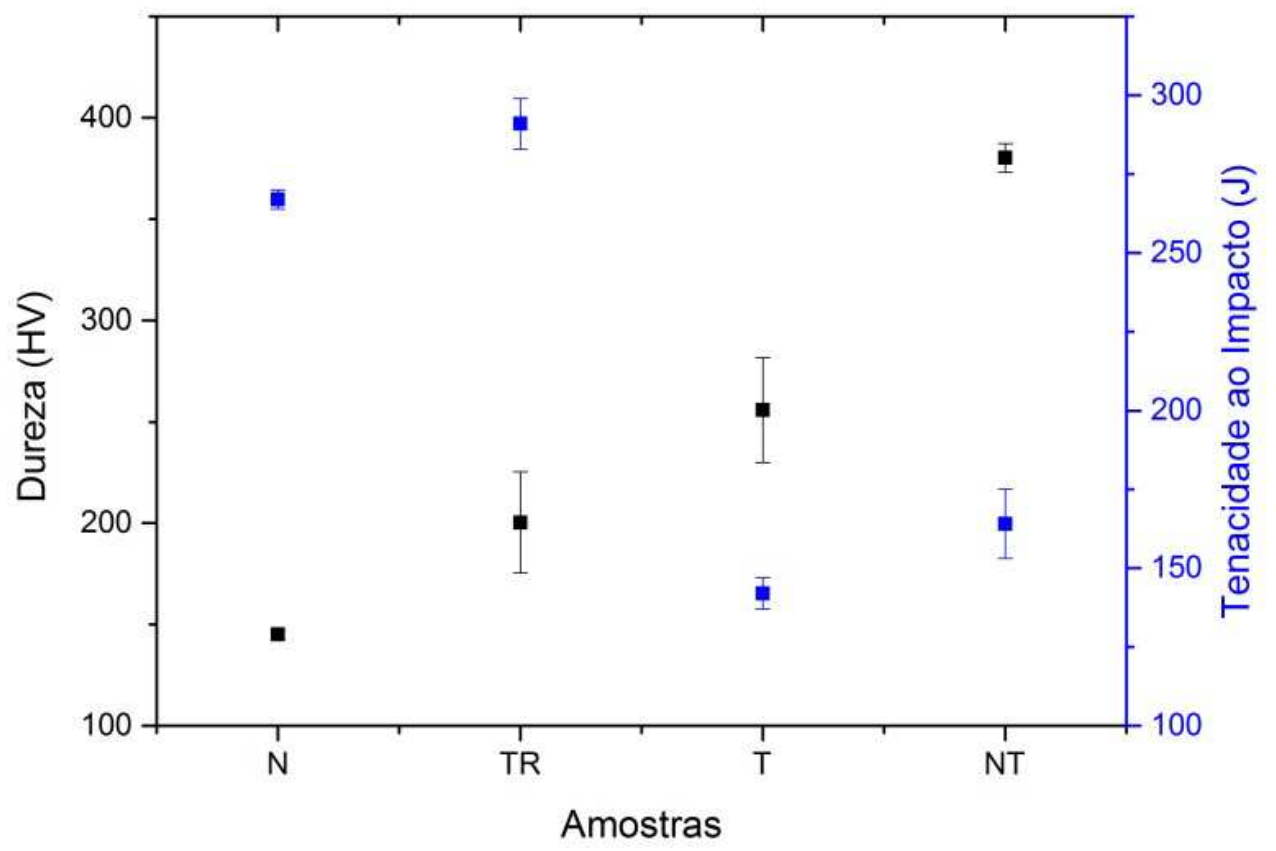

Figura 3. Dureza Vickers e tenacidade ao impacto dos aços termicamente tratados.

Utilizar o ensaio de dureza Vickers pode ser interessante para controle de processo devido à facilidade/simplicidade do experimento e por ser possível relacionar os resultados com a equação (1). A Equação 1 revela uma relação linear entre o limite de escoamento (LE) e a dureza Vickers (HV)[5].

$$
L E=2 \times H V+105(1)
$$

\subsection{Microestrutura}

A Figura 4 apresenta as microestruturas obtidas por microscopia óptica de todas as condições de tratamentos térmicosestudadas.

A Figura 4 (a) mostra uma estrutura constituída por ferrita e perlita, típica de um tratamento térmico de normalização, bem diferente das demais condições. Estesconstituintes conhecidamente contribuempara o aumento da ductilidade do materialquando comparados a outros como a bainita e a martensita [10]. As propriedades mecânicas avaliadas neste estudo corroboram com as características da microestrutura observada, pois a amostra normalizada apresentou o maior alongamento e menores valores de LE e LR comparada às demais, assim como uma boa tenacidade ao impacto a $0^{\circ} \mathrm{C}$. 


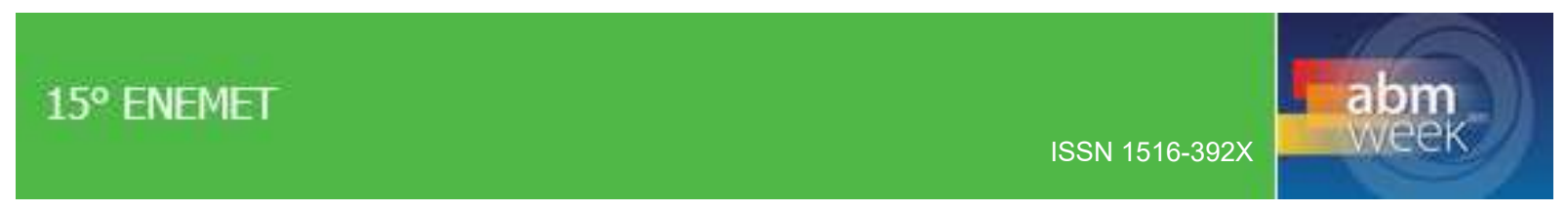

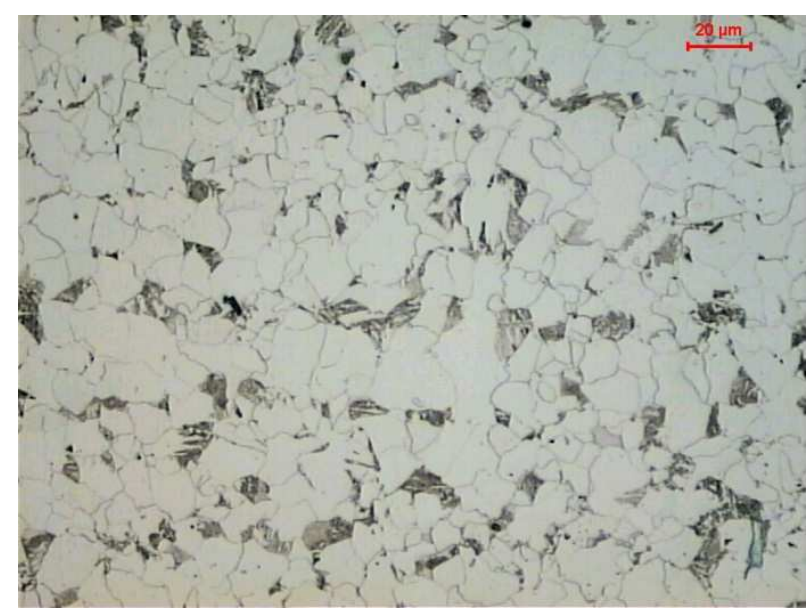

(a)

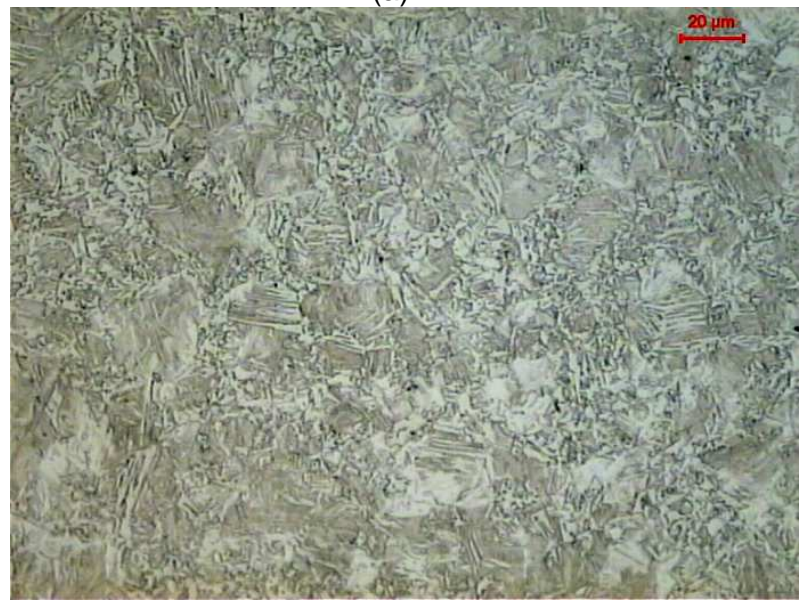

(c)

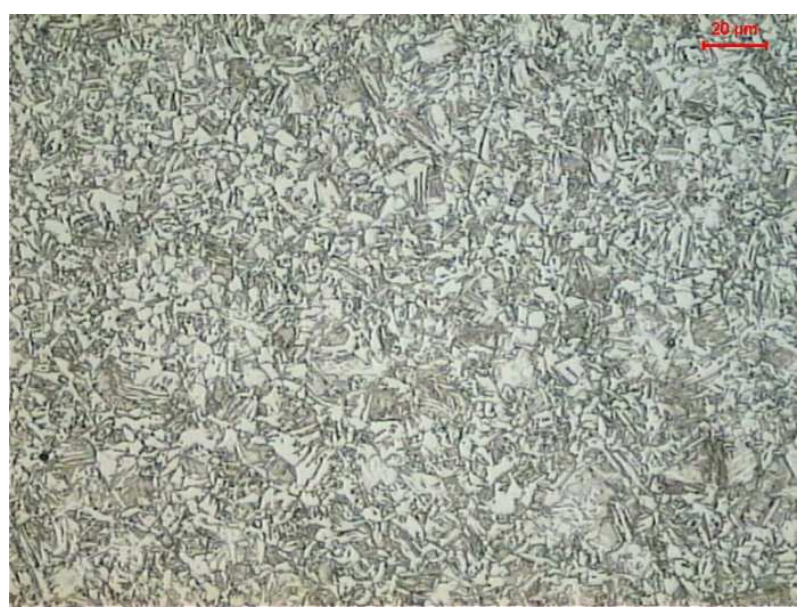

(b)

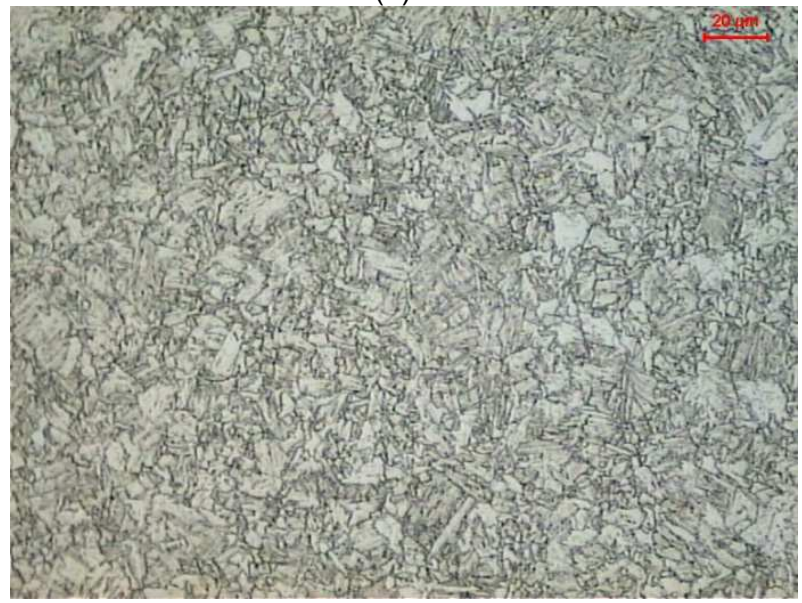

(d)

Figura 4.Microestruturas das amostras de aço no microscópio ótico: (a) normalizada - $N$, (b) normalizada e temperada - NT, (c) temperada - T e (d) temperada e revenida -TR - Ataque Nital $2 \%$ $500 \mathrm{x}$.

A microestrutura da condição NT pode ser observada na Figura 4 (b) onde se pode identificar a presença de bainita e martensitacomo constituintes majoritários e uma pequena fração de ferrita primária nos contornos de grão prévio da austenita (ferritaalotriomorfa). O mesmo pode ser dito a respeito da condição $\mathrm{T}$, apresentada na Figura 4 (c). Entretantodeve-se destacar que a microestrutura da amostra NT está significativamente maisrefinada, o que seria uma consequência do refino de grão inicial promovido pela normalização prévia, como objetivado.A Figura 4 (d) apresenta martensita e bainita revenidas, assim como uma fração de ferrita mais significativa em função da precipitação de carbonetos de ferro. Supõe-se que as amostras T e NT também apresentem uma pequena fração de constituinte MA [8].

De forma geral, pode-se afirmar que as microestruturas obtidas em cada condição de tratamento térmico estão de acordo com a composição química do aço, pois uma vez que se trata de um aço hipoeutetóide com baixo teor de carbono, sua cinética de formação de ferrita primária é ligeiramente acelerada, sendo difícil a obtenção de bainita sem a formação de pequena fração deste constituinte. A martensita pode ser justificada principalmente pela presença do boro, que está presente em uma concentração que favorece a temperabilidade deste tipo de aço. Deve-se destacar que a concentração máxima de nitrogênio neste aço é limitada a 0,010\%, justificando a pequena adição de elementos como alumínio e titânio (formadores de 
carbonitretos). O boro, neste contexto, estará disponível para contribuir com a transformação martensítica.

$\mathrm{Na}$ Figura 5, imagens feitas por microscopia eletrônica de varredura, com detalhes das microestruturas dos diferentes ciclos de tratamentos térmicos, são apresentadas e confirmam a presença dos constituintes já assinalados. Um detalhe da ferrita e da perlita é apresentado na Figura 5 (a). É possível observar martensita e bainita nas condições NT e T, representadas na Figura 5 (b) e (c). Tal observação explica a diferença nos valores de dureza entre as duas, visualizada na Figura 3, vistoqueaestrutura mais refinada apresenta um incremento na dureza [4]. A possível presença de constituinte MA poderia também explicar essa diferença significativa nos valores de dureza [8].

A microestrutura da condição TR é vista na Figura 5 (d). Nota-se martensita revenida e bainita começando a se decompor em carbonetos finamente dispersos e ferrita. Essa formação de carbonetos explica o aumento da energia absorvida no impacto e o decaimento da dureza comparada com as amostras T e NT.

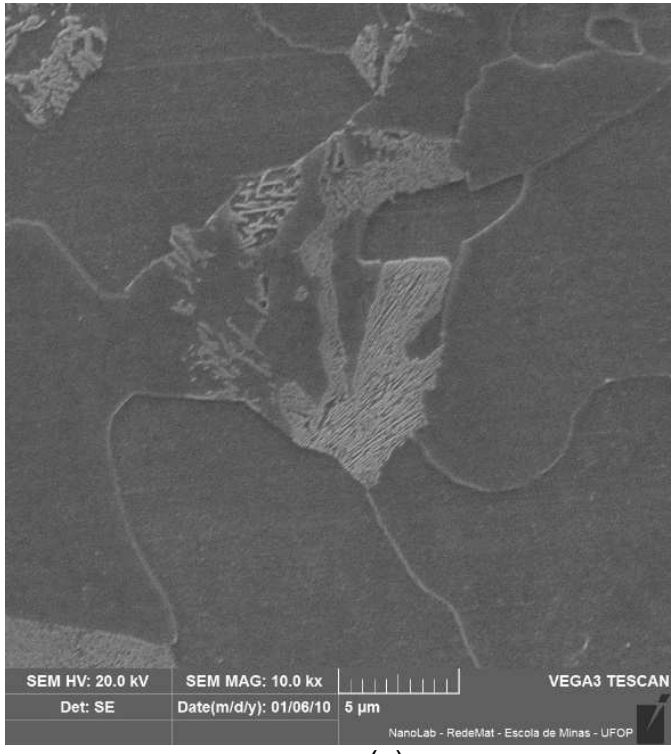

(a)

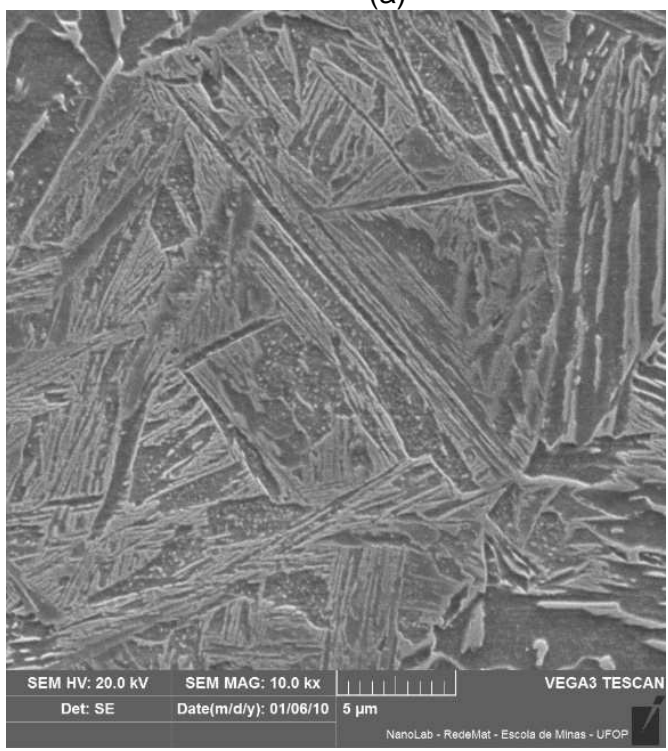

(c)

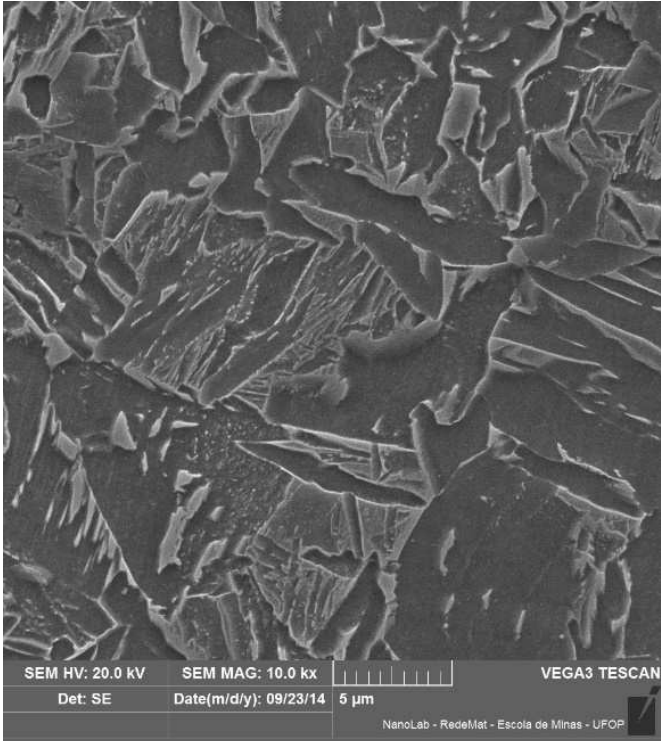

(b)

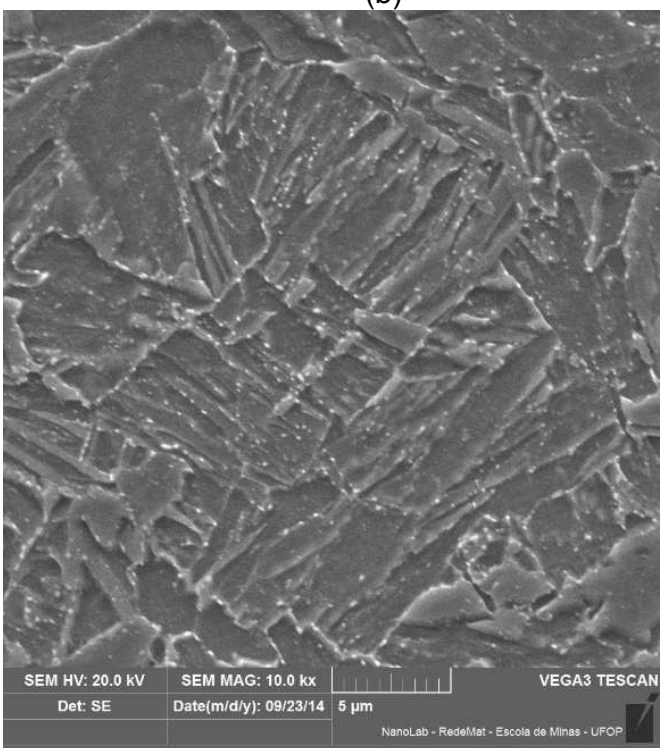

(d)

Figura 5. Microestruturas das amostras de aço no microscópio eletrônico de varredura: (a) normalizada - N, (b) normalizada e temperada - NT, (c) temperada - T e (d) temperada e revenida TR - Ataque Nital 2\% - 10000x. 


\section{CONCLUSÃO}

Os tratamentos térmicos estudados exerceram forte influência sobre as propriedades mecânicas e microestruturado aço estudado.

A amostra normalizada apresentou microestrutura constituída por perlita e ferrita, possuindo assim os menores limites de resistência mecânica e maior ductilidade.A amostra normalizada e temperada, assim como a temperada apresentam ferrita, martensita e bainita como constituintes. Já aquela temperada e revenida,apresentamartensita revenida e bainita começando a se decompor em carbonetos.

No contexto dos ensaios de mecânicos, apenas a amostra temperada e revenida (TR) atendeu às especificações do grau APIX65.A TR apresentou maior tenacidade atribuída ao alívio de tensões e ao início da decomposição da martensitae da bainita em carbonetosde ferro e ferrita.

\section{Agradecimentos}

À empresa Vallourece\& Sumitomo Tubos do Brasil - VSB e aos funcionários do Laboratório mecânico da mesma. Ao DEMET-UFOP e seus funcionários, assim como ao CNPq pelo apoio financeiro.

\section{REFERÊNCIAS}

1 Yergin D. O Petróleo - Uma história mundial de conquistas, poder e dinheiro. São Paulo: Editora Paz e Terra, 2010.

2 Morais J.M. Petróleo em águas profundas: uma história tecnológica da PETROBRAS na exploração e produção offshore. Brasília, 2013

3 Porto R. Avaliação da Influência de parâmetros de laminação de tiras a quente na tenacidade de um aço que atende aos requisitos da Norma API 5L, graus X70 e X80. Ouro Preto, 2010.

4 Godefroid L.B., Cândido L.C., ToffoloR.B.,.Barbosa L.H.S., Microestrutura e propriedades mecânicas de dois aços do tipo API para empregos de minerodutos. In: 20ํㅡㄹ Congresso Brasileiro de Engenharia e Ciência dos Materiais, 20, 2012. Joinville

5 Hashemi,S.H. Strength-hardness statistical correlation in API X65 steel. Materials Science and Engineering A. 2011; v. 528: p.1648-1655.

6 Catálogo ArcelorMittal: Stock Specifications. Disponível em :<http://ds.arcelormittal.com/repo/Technical\%20Data\%20Sheets/Seamless\%20Pipes\% 20-\%20API\%205L\%20grade\%20X65\%20PSL\%202.pdf> .Acessado em 11 de março de 2015.

7 American Petroleum Institute- API. API 5L - Specification for Line Pipe. 2004.

8 El-Danaf, E.; Baig, M.; Almajid, A.; Alshalfan,W.; Al-Mojil, M. e Al-Shahrani, S. Mechanical, microstructure and texture characterization of API X65 steel. Materials and Design. 2013; v. 47: p. 529-538.

9 ASM Metals Handbook, 1991. Heat Treating, ASM International, v. 4. 1991.

10 Sami, Z., Tahar, S. e Mohamed, H. MicrostructureandCharpyimpactpropertiesofferritemartensitedual phaseAPIX70linepipesteel. MaterialsScience\&Engineering. 2014; v. 598: p. 338-342.

11 Smirnov, M.A., Yu Pyshmintsev,I., Maltseva, A.N. e Mushina, O.V. Effect of ferritebainite structure on the properties of high-strength pipe steel. Metallurgist. 2012; v. 56: p. $49-51$.

12 ASTM E8/8M-13a - Standard Test Methods for Tension Testing of Metallic Materials, 2013. 
13 ASTM A370-12a - Standard Test Method and Def. for Mech. Testing of Steel Products, 2012.

14 ASTM E384-11e1 - Standard Test Method for Knoop and Vickers Hardness of Materials, 2011.

15 ASTM E23 - 12c - Standard Test for Bar Impact Testing of Metallic Materials, 2012.

16 Chiaverini, V. Tratamentostérmicos das ligas metálicas.7 ed. São Paulo: Associação Brasileira de Metalurgia e Materiais; 2008. 